\title{
UMA ANÁLISE DO INSTAGRAM E SUAS INTERFACES COM AS QUESTÕES CURRICULARES
}

\author{
AN ANALYSIS OF INSTAGRAM AND ITS INTERFACES \\ WITH THE CURRICULAR ISSUES \\ UN ANÁLISIS DEL INSTAGRAM Y SUS INTERFACES \\ CON LAS CUESTIONES CURRICULARES
}

SANDRO BORTOLAZZO

Roseli Belmonte Machado ${ }^{\mathrm{I}}$

'Universidade Federal do Rio Grande do Sul (UFRGS), Porto Alegre/RS, Brasil

\begin{abstract}
RESUmo O crescente uso de redes sociais, a exemplo do aplicativo Instagram, vem sinalizando outras formas de pensar a sociedade, a educação, a aprendizagem, o ensino e o currículo. Assim, esta análise problematiza algumas relações possíveis entre o Instagram e as questões curriculares. Inscrita no referencial dos Estudos Culturais em Educação a partir de uma perspectiva pós-estruturalista, três movimentos de investigação se interligam na composição do estudo. O primeiro movimento contextualiza o Instagram, com foco no seu caráter pedagógico. O segundo movimento apresenta um panorama sobre o currículo, suas ênfases e transformações. O terceiro e último movimento explora como o Instagram impulsiona outros modos de conceber e problematizar questões curriculares. Os resultados indicam a presença de um aplicativo de grande alcance que contribui para pensar um currículo móvel - amparado nos discursos das expertises - produzido para um tipo de aprendizagem afinada às tecnologias de base digital.
\end{abstract}

Palavras-chave: Currículo; Instagram; Aprendizagem Móvel.

ABSTRaCr The rising uses of social networking, such as the app Instagram, has been signaling other ways of thinking about society, education, learning, teaching, and the curriculum. Thus, this analysis problematizes some possible relationships between Instagram and curricular issues. Enrolled in the framework of Cultural Studies in Education from a post-structuralist perspective, three research movements are interconnected to compose the study. The first movement contextualizes Instagram, focusing on its pedagogical character. The second movement presents an overview of the curriculum, its emphases, and transformations. The third and final movement explores how Instagram drives other ways of conceiving and problematizing curriculum issues. The results indicate the presence of a wide-reaching application 
that contributes to think about a mobile curriculum, supported by the speeches of the experts, produced for a type of learning tuned to digitally based technologies.

Keywords: Curriculum; Instagram; Mobile Learning.

Resumen El uso creciente de aplicaciones de redes sociales, a ejemplo del Instagram, ha señalado otras formas de pensar la sociedad, la educación, el aprendizaje, la enseñanza y el currículum. Así, este análisis problematiza algunas posibles relaciones entre el Instagram y cuestiones curriculares. Inscritos en el marco de los Estudios Culturales en Educación desde una perspectiva posestructuralista, tres movimientos de investigación se interconectan para componer el estudio. El primer movimiento contextualiza el Instagram, centrándose en su carácter pedagógico. El segundo movimiento presenta una descripción general del currículum, sus énfasis y transformaciones. El tercer y último movimiento explora como el Instagram impulsa otras formas de concebir y problematizar cuestiones curriculares. Los resultados indican la presencia de una aplicación de amplio alcance que contribuye a pensar en un currículum móvil - apoyado por los discursos de los expertos - producido para un tipo de aprendizaje sintonizado con tecnologías de base digital.

Palabras Clave: Currículo; Instagram; Aprendizaje Mobil.

\section{INTRODUÇÃo}

O crescente número de usuários de redes sociais vem contribuindo para operar transformações na sociedade, que incluem não apenas a imersão dos sujeitos dentro uma racionalidade operada por meio das tecnologias digitais, mas mudanças nas formas de pensar a política, a economia, a educação, e assim por diante.

Em relação às questões educacionais, o aplicativo Instagram vem ganhando ascendência e tem sido utilizado para inúmeras finalidades: professores de escolas de idiomas ministram aulas; profissionais da área da saúde oferecem orientações aos pacientes; professores de educação física produzem e conduzem treinos; escolas profissionalizantes disponibilizam atividades e, mais recentemente, instituições regulares de ensino têm absorvido e lançado mão do Instagram como uma ferramenta de apoio pedagógico.

É possível notar ainda que, diante do quadro de pandemia e distanciamento social instaurado em meados de março de 2020, resultado do advento da SARS-COVID-19, as instituições de ensino tomaram o Instagram para usos pedagógicos, deslocando a ênfase anteriormente centrada nas ações de marketing. Quer dizer, muitas das publicações, antes da pandemia, se centravam em promover a escola da rede privada de ensino, comercialmente, ao passo que, depois do início da SARS-COVID-19, as postagens ganharam um tom mais pedagógico, mostrando as aulas gravadas pelos professores e os próprios alunos estudando em casa.

Este estudo, de caráter exploratório e bibliográfico, se encontra inscrito no referencial dos Estudos Culturais em Educação de uma perspectiva pós-estruturalista. O objetivo da análise está em problematizar algumas relações entre o Instagram e as questões curriculares. Dessa forma, três movimentos interligados de investigação estruturam a pesquisa. 
No primeiro movimento, o texto contextualiza o cenário social envolto pelas tecnologias digitais, mostrando o Instagram e suas ênfases pedagógicas. Neste primeiro movimento, os recursos do aplicativo e suas respectivas utilizações por parte de empresas, profissionais e instituições de ensino são apresentados. O suporte teórico do primeiro movimento se apoia em autores como Urry (2007), Wiktor (2012), Dion (2016), entre outros, que vêm problematizando questões referentes ao Instagram, à mobilidade e às aprendizagens.

No segundo movimento, evoca-se uma abordagem de inspiração pós-estruturalista sobre o currículo, destacando suas ênfases e transformações. O intuito é compreender os pressupostos que delineiam um tipo de organização curricular observada no aplicativo Instagram. Assim, é preciso assinalar que esta abordagem implica em um afastamento das formas unitaristas de compreender a sociedade. Trata-se, assim, de uma tentativa de analisar um aplicativo em expansão, partindo da ideia de currículo como um artefato que se expande para além das fronteiras espaço-temporais das escolas. Um tipo de currículo que transcende a lista de conteúdos e que, ao mesmo tempo, estabelece conexões com os diferentes espaços e atividades do cotidiano. Quer dizer, o currículo visto como uma construção produzida nas dinâmicas sociais, políticas e culturais de cada sociedade. Para tanto, toma-se por base as produções de autores de uma perspectiva pós-estruturalista, com destaque à Tomaz Tadeu da Silva (2007) e Alfredo Veiga-Neto (2010; 2014).

O último movimento explora como o aplicativo Instagram impulsiona modos distintos de problematizar questões curriculares. Não se trata, portanto, de uma análise fechada, mas de um conjunto de perspectivas que estimulem pensar o currículo de outras formas. Perspectivas que compreendem o currículo para além da institucionalidade escolar ou acadêmica, e que expandem seus lugares de produção e operação.

\section{INSTAGRAM E MOBILIDADE: UMA ENTRE MUITAS REDES SOCIAIS}

A metáfora da "rede" se destaca em vários estudos que envolvem as tecnologias digitais. Isso porque o sentido da palavra "rede", no contexto tecnológico, evidencia a possibilidade, tanto social quanto técnica, de usuários formalizarem relações. Assim, os vínculos estabelecidos nas redes não podem ser analisados fora de uma lógica de sociabilidade e de consumo programadas pelas plataformas digitais.

As redes sociais podem ser consideradas estruturas produzidas na internet e formadas por pessoas e organizações que se conectam a partir de interesses em comum. Essas mesmas redes sociais, a exemplo do Facebook ou mesmo do Twitter, nas suas configurações iniciais, eram apenas sites. Hoje, ambas se converteram em aplicativos para telefones celulares.

O caso do Instagram, por sua vez, é distinto. A rede social Instagram $^{1}$ não nasce enquanto site, mas como um aplicativo e, portanto, se inscreve diretamente no universo de aplicativos para telefones celulares.

Desenvolvido pelos engenheiros Kevin Systrom e Mike Krieger, o Instagram teve seu lançamento ao público em outubro de 2010, sendo inicialmente projetado com o intuito de resgatar as nostálgicas e clássicas fotografias registradas pelas câmeras Polaroid. Em 2012, o aplicativo foi vendido ao Facebook e, no momento, ambas as redes atuam em colaboração, ou seja, elas se utilizam dos mesmos recursos para compartilhar fotos, vídeos, etc. 
De acordo com Dion (2016), a ênfase na publicação de imagens é o que diferencia o Instagram de outras redes sociais. O aplicativo é considerado o protagonista das selfies, fenômeno em que os sujeitos fotografam a si mesmos a partir da câmera frontal dos telefones celulares. Na análise de Dion (2016), ao contrário do Facebook - ainda que opere na mesma lógica, em que usuários estão conectados, geralmente, a amigos e familiares - no Instagram é permitido seguir empresas, marcas, instituições, artistas, celebridades, e assim por diante, de um modo mais rápido e com maior apelo de consumo.

Dentro do aplicativo são encontrados diversos recursos. Na página inicial de cada usuário é possível editar informações sobre o perfil, incluindo uma breve biografia, uma foto em formato circular e a visualização do número de postagens e seguidores. Importante alertar que cada conta pode ser configurada como pública ou privada. Nas contas públicas, qualquer usuário pode virar seguidor, ao passo que, nas contas privadas, uma autorização deve ser solicitada.

$\mathrm{Na}$ área destinada ao conteúdo do perfil, os seguidores têm acesso às postagens e, ao clicar em uma determinada foto, o aplicativo a exibe em uma versão ampliada. Em cada postagem, os seguidores podem curtir a foto, deixar comentários, marcar outras pessoas ou ler comentários postados anteriormente.

Ao selecionar uma foto, há possibilidades de manipular a imagem utilizando-se de filtros. Ademais, ao publicar fotos ou vídeos, os usuários podem incluir a localização, especificando o local da foto e, gerando, assim, uma galeria de publicações daquela mesma localidade. É possível também marcar amigos através do símbolo@ seguido pelo nome do usuário e adicionar hashtags (\#) com palavras-chave, colaborando, dessa forma, para associar importância a um determinado tema, campanha, ideia, etc.

Dentre outros recursos, destacam-se os stories. Trata-se da publicação de fotos e vídeos rápidos, editados em sequência, e visualizados por um período curto de tempo (24 horas). Em 2013, o Instagram se tornou uma plataforma de suporte a vídeos curtos, de até 15 segundos. Em 2018, o recurso mais recente do aplicativo foi lançado, o IGTV, ferramenta que permite gravar vídeos com maior duração. A partir do IGTV, o Instagram se insere no universo digital das transmissões por vídeo, tendo as lives enquanto fenômeno emergente. Com a inserção de vídeos, o Instagram passa a concorrer com outras redes, como o YouTube. Da mesma forma que ocorre no YouTube, com o IGTV, cada usuário pode criar seu próprio canal.

De acordo com o site oficial do Instagram, em 2020, o aplicativo já ultrapassou a marca de 1 bilhão de usuários. O que se tem observado também é que a plataforma se tornou um espaço de narrativas, discursos, promoções, campanhas e aprendizagens destinadas a um público cada vez mais diverso e heterogêneo. No Instagram, há um universo de publicações, variando desde imagens sofisticadas de paisagens, até postagens sobre alimentos, saúde, viagens, exercícios físicos, etc.

O aplicativo vem sendo utilizado com distintos propósitos. Há usuários promovendo a si mesmos, outros apenas acompanham a vida de amigos e artistas. Empresas mostram suas marcas e produtos; profissionais liberais oferecem serviços; agências de viagens divulgam pacotes. Contudo, um uso mais recente do Instagram tem se dado por profissionais liberais, a exemplo de psicólogos, nutricionistas, médicos, professores de educação física 
e instrutores de idiomas estrangeiros, que encontraram no aplicativo um suporte comercial e pedagógico. Pedagógico porque as publicações no Instagram, de certa forma, ensinam e estimulam determinadas formas de ver, de pensar e de agir sobre o mundo ao nosso redor.

Wiktor (2012), em estudo quanto ao uso do Instagram para aprendizagem de idioma estrangeiro, afirma que são vários os recursos pedagógicos do aplicativo - apresentação dos conteúdos por meio de figuras, mapas, planos, vídeos, músicas, textos, stories, desafios, lives, charges, tutoriais, jogos, dentre outros.

Simons e Masschelein (2014), na mesma perspectiva, evidenciam que o campo da aprendizagem vem se transmutando de ambientes fechados, como o das salas de aula, a eventos de aprendizagem que podem ocorrer a um simples toque na tela. Esses eventos operam enquanto uma estratégia de subjetivação. Quer dizer, no Instagram, os conteúdos estão disponíveis de acordo com os interesses de cada um. Assim, a perspectiva das individualidades fomentada no Instagram produz subjetividades e formas de aprendizagens que vão além daquelas institucionalizadas. Trata-se de um tipo de aprendizagem atravessado por desejos, vontades e necessidades específicas.

No compartilhamento de informações e saberes entre seus usuários, o Instagram dissemina a ideia do aplicativo enquanto um produto digital utilizado para questões relacionadas ao trabalho, lazer, saúde, nutrição, idiomas, economia, política, história, etc., provocando também um entendimento da ideia de educação e aprendizagem como de responsabilidade individual de cada sujeito.

O deslocamento no entendimento sobre aprendizagem, ultrapassando as barreiras institucionais, interessa ser analisado no Instagram, uma vez que a própria interação dos sujeitos junto às telas de telefones celulares vem produzindo outras formas dos sujeitos habitarem o contemporâneo. Um contemporâneo que se encontra em constante mobilidade.

Seguindo a orientação de Urry (2007), há um novo tipo de sociologia, ou seja, uma movimentação da sociedade que funciona em mobilidade. A mobilidade, neste sentido, se dá em contraste à morfologia social fundada nas sociedades territorialmente fixadas. São as tecnologias móveis que, de certa forma, vêm capacitando os sujeitos a viver em mobilidade.

A mobilidade em si não está atrelada apenas à portabilidade de telefones celulares, mas diz respeito às novas experiências dos sujeitos com as plataformas digitais. A mobilidade configura certo estilo de vida ao produzir, inclusive, modelos de negócios que se apoiam completamente na mobilidade, tais como o dos aplicativos de transporte, do acesso a livros, filmes e músicas.

É, portanto, dentro desta linha argumentativa, que seria possível conjecturar a emergência de um tipo de aprendizagem ao estilo móvel. Para Traxler (2007), a aprendizagem móvel não se remete isoladamente à mobilidade ou à aprendizagem, mas parte da concepção de uma sociedade em mobilidade. O termo "aprendizagem móvel" pressupõe o uso de dispositivos digitais para fins educacionais e implica, segundo Traxler (2007), a interdependência de três elementos: a mobilidade da tecnologia, ou seja, da possibilidade de artefatos digitais como smartphones e tablets serem transportados facilmente; a mobilidade da aprendizagem, como a dos recursos e meios educacionais disponíveis junto às plataformas digitais; e a mobilidade dos sujeitos, que significa a não restrição aos espaços institucionalizados de escolas e universidades. 
Tanto a mobilidade da tecnologia quanto da aprendizagem e dos sujeitos permitem uma educação contínua. O Instagram, mas não apenas ele, deu visibilidade à aprendizagem móvel e tem fornecido aos seus usuários outras experiências e formas de representar aspectos da vida social, profissional, política e privada, modulando e orientando aprendizagens regidas por novas sensibilidade. O Instagram é um recurso material da cultura contemporânea e, dentro da perspectiva adotada nesta pesquisa, também é um agente na produção das subjetividades.

O Instagram é representativo de uma sociedade apoiada no digital, de sujeitos que se encontram inscritos na racionalidade neoliberal dos investimentos em si. Importa marcar que a ideia de neoliberalismo é compreendida, nesta pesquisa, a partir das contribuições de Michel Foucault sobre o modelo neoliberal norte-americano. Nesse modelo, o neoliberalismo é entendido como forma de vida. É um modo de pensar e de agir em que se estendeu a racionalidade do mercado a domínios não exclusivamente ou não prioritariamente econômicos (FOUCAULT, 2008).

Além da racionalidade neoliberal, há um entendimento emergente de governos, meios de comunicação e dos próprios sistemas de ensino que propagam a ideia de uma aprendizagem contínua ao longo da vida, ou no que Williams (1996) denominou como educação permanente. Nesse sentido, o Instagram está afinado com essa lógica.

A partir disso, cabe pensar como seria a produção de um currículo alinhado a essas discussões, ou seja, que esteja em sintonia com uma sociedade cambiante, flexível e móvel? Considera-se que o aspecto desafiador de utilizar o Instagram como objeto de estudo para pensar o currículo é trazer ao debate a ideia do artefato "currículo" - importante e essencial ao funcionamento das instituições escolares - como um elemento aberto e fluído.

\section{CURRÍCULO: DESLOCAMENTOS E ÊNFASES CONTEMPORÂNEAS}

Inicialmente, é necessário trazer ao debate o entendimento de currículo assumido nesta análise. Apesar das teorias curriculares apontarem sentidos diversos a respeito do que é o currículo, há uma tradição que entrelaça a ideia de currículo com o que a escola deve ensinar. Por um viés, o currículo tem se constituído como um elemento organizador, tanto das rotinas escolares, quanto do fazer pedagógico, definindo caminhos, trajetórias e demonstrando aos sujeitos o que se espera deles.

Compreende-se que campo curricular se encontra constantemente afetado, seja pelas tensões entre os diferentes paradigmas, seja pelas atualizações e transformações dos saberes. Este estudo, assim, se afasta de posturas curriculares binárias que simplesmente legitimam alguns saberes e outros não. Essa investigação busca compreender como as diversas práticas cotidianas, sobretudo àquelas que se utilizam dos aplicativos digitais, podem adentrar às discussões curriculares.

É preciso sinalizar que esta é apenas uma forma de olhar para o currículo, de inspiração pós-estruturalista, e que não define um método a priori. O caminho percorrido na análise implica, inicialmente, um afastamento da Modernidade e das suas formas unitaristas de compreender a sociedade. Exploram-se potencialidades pós-estruturalistas, partindo da ideia de currículo como um processo em que os sujeitos de uma determinada sociedade, 
tangenciados pelo caráter histórico e social, são conduzidos a agir sobre si mesmos e sobre o mundo ao seu redor. Todavia, ainda assim, é preciso retomar alguns caminhos e posicionamentos do campo do currículo, considerando seu a priori histórico. Isso é profícuo para problematizar os acontecimentos presentes.

Para realizar esse empreendimento de retomar a constituição do campo do currículo a fim de problematizar as questões do presente, recorremos a autores que têm se debruçado sobre esse tema. De acordo com Veiga-Neto (2010), o currículo pode ser entendido como um artefato cultural inventado há pouco mais de quatro séculos para colocar ordem na educação escolar. O currículo funcionou como maquinaria disciplinar, uma máquina espaço-temporal a formar e a formatar indivíduos disciplinares. Sua invenção está relacionada com um embate nos primórdios da Modernidade "entre duas frentes: uma delas, um pouco mais antiga, à frente a favor do plano da imanência; a outra, a frente a favor do plano da transcendência" (VEIGA-NETO, 2010, p. 4). Para o autor, por ser um artefato baseado na disciplina, na ordem e na representação, o currículo identificava-se com o plano da transcendência, colocando-se em oposição à imanência.

Assim, o currículo não deve ser entendido e problematizado numa dimensão reduzida à epistemologia tradicional, ou numa dimensão restrita a qualquer ideologia, seja ela de matriz política, econômica, cultural ou mesmo filosófica. "Ele deve ser pensado a partir de complexas miradas sobre o social; miradas ao mesmo tempo panorâmicas e focais, abrangentes e específicas, disciplinares e transdisciplinares, macroscópicas e microscópicas" (VEIGA-NETO, 2014, p. 1).

Silva (2007), na obra "Documentos de Identidade", nos oferece um modo de ver e de pensar a constituição das diferentes teorias do currículo. Segundo o autor, as teorias do currículo estão implicadas na produção do próprio conceito, inventando-o, ao mesmo tempo em que o descrevem. Dentre as abordagens curriculares destacadas pelo autor, estão os estudos realizados nos Estados Unidos (anos 1920) num contexto de processos imigratórios, industrialização e massificação da escolarização. Nesse momento, o currículo era pensado como um modo de racionalização dos resultados educacionais rigorosamente planejados e medidos. Seria uma teoria tradicional do currículo centrada em questões técnicas de como transmitir conhecimento e saberes dominantes já selecionados e considerados inquestionáveis.

Em continuidade, Silva (2007) descreve o contexto da década de 1960 e os deslocamentos na forma de pensar o currículo. Para o autor, no âmbito das transformações e dos movimentos revolucionários de direitos civis, de independência das antigas colônias europeias e de protestos estudantis na França, surgem teorizações que problematizam a estrutura educacional tradicional. Seriam, assim, os primeiros indicativos das teorias críticas do currículo que "efetuam uma completa inversão nos fundamentos das teorias tradicionais" (SILVA, 2007, p. 29), deslocando a preocupação do "como fazer" para pensar em "o que o currículo faz".

O autor avança suas colocações e dispõe sobre as chamadas teorias pós-críticas do currículo, afirmando que é a questão do poder que vai separar as teorias tradicionais das críticas e das pós-críticas. As teorias pós-críticas estenderiam a compreensão dos processos de dominação evidenciados nas teorias críticas, pois passariam a analisar a "dinâmica de poder envolvida nas relações de gênero, etnia, raça e sexualidade" (SILVA, 2007, p. 146). 
Há um deslocamento no entendimento sobre currículo. Após as teorias críticas e pós-críticas, não é mais possível pensar o currículo pela ótica dos conceitos de ensino e eficiência. Agora, emergem as relações de poder-saber que se estabelecem, assim como seus efeitos nas subjetividades dos sujeitos.

Para pensar o aplicativo Instagram junto às questões curriculares, talvez seja preciso deslocar a ideia de currículo enquanto uma grade composta de unidades de ensino predefinidas, e apreendê-lo enquanto construção social, historicamente datado e localizado. Há uma compreensão de currículo que se alinha à perspectiva sócio cultural proposta por Moreira (2008) ao afirmar que, no processo curricular, há uma tensão entre dois focos. De um lado, o conhecimento escolar e, do outro lado, a cultura. Isto significa que o currículo envolve a esfera escolar, mas também está comprometido com suas transformações, ou seja, com as práticas culturais de cada sociedade.

Assim, desenvolver uma análise pós-estruturalista pensando Currículo e Instagram implica na desconstrução de certas narrativas. Desconstruir, na perspectiva de Derrida e Roudinesco (2004), não é negar a racionalidade da filosofia ocidental, mas agitar seus alicerces, desorganizar os discursos e mostrar seus distintos funcionamentos.

Os escritos de Bauman (2010) sinalizam deslocamentos na ideia de Educação e de currículo. Na Modernidade Sólida, havia um projeto em que a formação do ser humano era "responsabilidade plena e exclusiva da sociedade como um todo, em especial de seus legisladores" (BAUMAN, 2010, p. 103). Isso é, o Estado é quem devia guiar as condutas dos sujeitos e formar seus respectivos cidadãos. As narrativas da educação na Modernidade Sólida eram finitas e sequenciais.

Em contrapartida, uma educação pensada sob a égide das tecnologias digitais encontra no capitalismo informacional (CASTELLS, 1999) um currículo ancorado em métodos just in time, e que atendem às escolhas e às demandas individuais. Assim, um currículo moldado para a Modernidade Líquida (BAUMAN, 2009), usando a metáfora de Bauman, talvez possa ser visto enquanto algo fluído, móvel, cambiante e com características afinadas às estratégias de vida nas sociedades contemporâneas.

Aliada ao projeto moderno, a instituição escolar rejeitava a ambivalência, o caos e a desordem. No entanto, o que se observa diante das contingências contemporâneas, não é mais uma educação ordeira, mas uma flexível, fragmentada e que tem produzido sujeitos aptos a lidar com as incertezas e as constantes adaptações.

O Instagram enquanto objeto de análise é visto como um artefato significativo à produção de saberes. Quer dizer, esse tipo de abordagem pode ser expresso em, ao menos, dois âmbitos. Um primeiro âmbito seria pensar o currículo a partir de uma descentralização na transmissão de conhecimentos, ou seja, entender que os conteúdos podem ser acessados a qualquer momento e em qualquer lugar. Um segundo aspecto está relacionado à mobilidade dos artefatos digitais. Assim como os meios de transporte afetaram a percepção dos sujeitos em relação à velocidade, os artefatos digitais nos revelam distintas formas de circulação e aquisição de conhecimento. Nesta perspectiva, entende-se o currículo como um artefato cultural, criado na contingência da Modernidade, e que vem sendo produzido e produzindo diferentes racionalidades e sujeitos. 
$\mathrm{Na}$ esteira da racionalidade neoliberal como modo de vida, que clama por sujeitos flexíveis, empresários de si e autorregulados, a concepção de currículo está intrínseca a essa lógica. Para Veiga-Neto:

Na contemporaneidade, o currículo continua a ter um papel decisivo na individu-
ação. Mas agora ele opera não tanto pela via do poder disciplinar, mas por dispo-
sitivos de controle, normatização e normalização. Portanto, o currículo continua
envolvido no engendramento, difusão e legitimação de um novo tipo de socie-
dade, agora povoada por novas subjetividades cada vez mais flexíveis, líquidas,
voláteis, inacabadas, cosmopolitas e performativas. (VEIGA-NETO, 2014, p. 3).

Pode-se afirmar que a ideia de currículo se deslocou, considerando suas dimensões filosófica, epistemológica, política, cultural, antropológica, psicológica, econômica, etc. Os projetos de currículo foram produzidos e endereçados a um tipo de educação pensada em racionalidades diferentes, refletindo valores, crenças, concepção de homem e de vida de determinados períodos. Isso nos abre a possibilidade de pensar na mudança de ênfase, ou seja, nos deslocamentos de espaço e de tempo em que se produzem os currículos.

\section{SOBRE UMA ORGANIZAÇÃo CURRICULAR MÓVEL}

Uma análise do Instagram parte da ideia do aplicativo como um objeto empírico presente no cotidiano de milhões de pessoas e como um objeto em constante transformação. Dentro dessas assertivas, três pontos de problematização merecem destaques. São eles: a) os diversos usos do Instagram podem se relacionar a um currículo que vem sendo produzido para um sujeito do neoliberalismo; b) da mesma forma que os currículos escolares, o Instagram vem enfatizando o poder dos discursos das expertises; c) o Instagram enquanto ferramenta pedagógica ajuda a fomentar um tipo de aprendizagem ao estilo móvel e personalizada.

Sobre o primeiro ponto, parte-se da retomada sobre o neoliberalismo. Compreende-se que hoje, em que pesem outras considerações, o neoliberalismo é entendido como uma forma de vida e de "governamento sobre a vida" (VEIGA NETO, 2014, p. 3), sendo a concorrência sua marca mais relevante. Na perspectiva do neoliberalismo norte americano, consolida-se a imagem do "homem competitivo, responsável por si mesmo, pelo seu sucesso, pelo seu futuro e profundamente dependente da economia" (VEIGA NETO, 2014, p. 5). A Teoria do Capital Humano, nesse sentido, parece ser a manifestação mais elaborada do neoliberalismo.

Segundo Foucault (2008, p. 272), o capital humano está implicado no "conjunto dos investimentos que se tem feito no homem mesmo". Os investimentos educativos são elementos essenciais, já que é por meio deles que o indivíduo vai se qualificando e maximizando seu capital humano. Investimentos que, embora atravessados pela aprendizagem escolar ou mesmo profissional, também as ultrapassam (FOUCAULT, 2008).

Tomando o Instagram, é possível afirmar que as estratégias utilizadas pelos seus usuários/consumidores têm como foco um sujeito empreendedor. Quer dizer, há uma promoção e disseminação, especialmente nas searas educativas, de um discurso que busca fazer que os sujeitos sejam empreendedores de si mesmos. E, como tal, também sujeitos flexíveis e 
adaptáveis. Ademais, é relevante sublinhar que a produção deste tipo de sujeito vem sendo enaltecida e associada a uma visão de futuro e de progresso atrelados ao digital. Tais argumentações são fruto de uma sociedade inscrita num regime tecnológico incessante que estimula cada vez mais o uso das ferramentas digitais.

A racionalidade neoliberal possibilitou certa flexibilização e expansão dos lugares e espaços em que vemos o currículo operando, ou seja, constituindo sujeitos e formas de vida. As redes sociais ingressaram no nicho da educação, colocando em prática um tipo de currículo voltado aos investimentos em si mesmo. No neoliberalismo, cada indivíduo constrói seu capital cultural e fica responsável por ele. Ao mesmo tempo, esse indivíduo passa igualmente a ser o resultado daquilo que ele mesmo vem construindo como seu capital.

O segundo ponto de destaque é sobre o currículo produzido no Instagram encontrar apoio nos discursos das expertises. Qualquer currículo é construído por meio de inúmeras negociações, mas, sobretudo, está pautado por autoridades que lhes conferem legitimidade e credibilidade. No entanto, enquanto percurso de aprendizagem de cada um e pensado para uma sociedade integrada ao digital, o currículo necessita de diversos tipos de autoridades.

A dispersão de autoridades é uma refração das mudanças sociais que vêm ocorrendo nas próprias experiências de vida cotidiana. $\mathrm{O}$ discurso das autoridades se ancora nas relações de poder que, na perspectiva foucaultiana, está intimamente relacionada ao saber, isto é, aquele que constitui verdades a partir de determinados saberes (FOUCAULT, 1992).

Autoridades e especialistas são legitimados socialmente a intervir na vida dos sujeitos em diversas esferas, como a da escola, dos ambientes de trabalho e familiares, no âmbito da saúde, do corpo, da beleza. Assim, compreende-se junto com Miller e Rose (2012) que a linguagem dos experts se direciona tanto a um conjunto de profissionais - como é o caso dos educadores que buscam objetivos particulares - quanto para outros que demandam uma orientação mais específica para administrar uma casa, uma empresa, melhorar a saúde, aprender idiomas, e assim por diante.

Ao usar a noção de "expertise", mais do que um grupo de profissionais legitimados a falar e comentar sobre determinado assunto, Rose (1998) chama atenção para a sua heterogeneidade, ou seja, não há um corpo unificado de teorias, mas uma combinação de informações e técnicas que produzem um complexo de saberes. Esses, por sua vez, são difundidos através de materiais institucionais, políticos, pedagógicos, midiáticos e de entretenimento: cursos, livros, jogos, reportagens, programas televisivos, leis, diretrizes, etc. E, agora, na sua versão contemporânea, estão multiplicados nas vozes de milhões de seguidores via Instagram. $\mathrm{O}$ aplicativo pode ser compreendido como um território de produção discursiva que fortalece concepções incita certas formas de comportamento, faz falar as "expertises", ilustra acontecimentos, narra trajetórias, ensina e, por isso, acaba criando possíveis realidades e verdades sobre a nossa sociedade.

É importante mencionar que os usuários do Instagram, geralmente, invocam uma estratégia proclamada de "discurso compartilhado" que, nos dizeres de Fulton et al. (2005, p. 247), juntamente com um conjunto de valores e crenças compartilhadas sobre o mundo, "endereçam ao seu público um discurso que lhes parece familiar". Algo com que podem se reconhecer, identificar e pertencer. Psicólogos, médicos, economistas, especialistas em autoajuda, nutricionistas, educadores físicos, advogados, pedagogos, entre outros, configu- 
ram fontes formais de autoridade, sendo muitos dos seus discursos transportados e reproduzidos no Instagram.

O Instagram utiliza das expertises para angariar seguidores, promovendo assim, médicos, psicólogos, professores de idiomas, etc. Um exemplo emblemático em tempos de pandemia é o aumento significativo dos perfis de infectologistas e epidemiologistas que usaram o aplicativo para disseminar informações.

Um terceiro elemento de análise difunde a ideia do Instagram enquanto uma ferramenta pedagógica que promove aprendizagens personalizadas e ao ritmo de cada um. Quer dizer, o Instagram dispõe de ferramentas que auxiliam um tipo de aprendizagem conforme preferências e projetos pessoais. O indivíduo e suas escolhas encontram lugar em um sistema de comunicação que proporciona autonomia e interatividade. Trata-se aqui, não do individualismo egoísta, mas daquele que pode ser organizado de acordo com a disponibilidade de tempo e o ritmo de cada um. O foco deste tipo de individualismo está no desenvolvimento pessoal, nas escolhas e nos projetos de vida.

Um currículo em consonância às novas linguagens e sistemas tecnológicos digitais incluem aprendizagens capazes de possibilitar caminhos para o desenvolvimento e execução de projetos de vida. O projeto de vida é um componente curricular que ultrapassa a institucionalidade, promovendo uma convergência dos interesses pessoais, dos contextos e das histórias de vida de cada um.

As três abordagens analíticas permitem conceber a ideia de um currículo aberto e fluido. Utilizar o Instagram para pensar o currículo expressa concepções de educação e de aprendizagem enquanto processos descentralizados, distribuídos e dispersos. De uma tradição curricular institucionalizada e desenvolvida nas dependências das escolas e universidades, há um acento para um currículo descentralizado e inscrito a partir de aprendizagens que ocorrem ao simples manusear das telas de telefones celulares.

Manovich (2001) reconhece que as telas digitais são agentes de mediação e um dos produtos pelas quais a cultura vem sendo produzida. As telas de smartphones, outrora ferramentas úteis apenas à telefonia móvel, se transmutaram a filtros que suprem e, muitas vezes, substituem a tela do cinema, da televisão e das páginas de livros. A visualização não é mais uma questão apenas de olhar e receber imagens, mas implica movimento.

O currículo, assim, não é simplesmente um corpo de conhecimento, mas resultado de um processo ativo entre os agentes da sociedade, que incorporam aspectos políticos, econômicos e culturais das suas realidades. Um aplicativo como o Instagram mostra o quão borradas estão as fronteiras entre educação formal e informal, entre currículo escolar e não escolar. Revela também que um tipo de educação orientada ao interesse pessoal já pode ser imaginado como um espaço de exploração para novas organizações curriculares.

As conexões entre Instagram e currículo, encadeadas na ideia de uma aprendizagem móvel, personalizada e afinada ao sujeito neoliberal, envolve uma combinação de interesses, sensibilidades e estilos de vida. No entanto, importa compreender que, mesmo diante dos avanços tecnológicos, a apropriação e os usos das tecnologias digitais ainda são elementos subjetivos e perversos. Isso porque nem todos têm a oportunidade de consumir e usufruir das benesses tecnológicas, e mesmo aqueles que tenham acesso podem, por sua vez, não se interessar. O impacto tecnológico não é universal. 
Além disso, e por um lado o Instagram convoca seus usuários a experimentar outras formas de aprendizagens - o que pode ser celebrado por muitos -, por outro lado, há uma redução de outros elementos que compõem o espectro educativo que, por vezes, fica limitado a um treinamento ou acúmulo de informação. Algo que vai na direção do que Bauman (2009) argumentou ao afirmar que a "bagagem de conhecimentos" não mobiliza a sociedade de hoje, já que ela se encontra pautada pelo descarte. O currículo que se apresenta no Instagram pode ser aquele atrelado a um tipo de educação "oferecido pelos programas de software" (BAUMAN, 2009, p. 663), com uma formação aligeirada, de curto prazo e orientada à demanda do mercado.

\section{CONSIDERAÇõeS}

Ao retomar o objetivo da análise, destaca-se que a invasão de smartphones e o uso de aplicativos para as mais diversas atividades vêm engendrando novas dinâmicas sociais. $\mathrm{O}$ Instagram, não apenas opera transformações nas formas como os sujeitos conduzem suas vidas, mas também tem permitido outras formas de compreender a aprendizagem para além dos espaços institucionalizados. Um tipo de aprendizagem móvel que se dá ao longo de toda a vida encontra ressonância nos discursos e publicações do Instagram, pois o aplicativo é parte do aparato material de uma era de livre mercado neoliberal, que confere aos sujeitos infinitas possibilidades de escolhas.

As marcas registradas e produzidas por artefatos digitais, a exemplo do aplicativo Instagram, têm feito repercutir igualmente uma ideia da aprendizagem como algo volátil e em constante atualização. Uma ideia de aprendizagens feitas sob medida ao gosto dos sujeitos. Nesse sentido, junto a sujeitos que se encontram em constante mobilidade, organizações curriculares móveis e capazes de se adaptar a este sujeito também emergem. Assim, talvez seja possível pensar que, por intermédio da vivência de organizações curriculares móveis, os sujeitos também vivenciem o currículo deste tempo de um modo mais fluido.

Um tipo de currículo aberto e que ainda se apoia veementemente no discurso das expertises é particularmente enaltecido em uma lógica neoliberal que responsabiliza e identifica os sujeitos como capazes de desenvolver habilidades e de aprender por conta própria. Todavia, é preciso dizer, por vezes, tais formações ocorrem de forma aligeirada, superficial e de qualidade duvidável.

Importa esclarecer ainda que este tipo de análise não é findável, justamente porque seus elementos constituintes são constructos móveis e em constante transformação. Portanto, um dos desdobramentos desta análise está em aprofundar a relação do Instagram com o currículo escolar e as práticas pedagógicas docentes.

\section{REFERÊNCIAS}

BAUMAN, Zygmunt. Tempos líquidos. Trad. Carlos Alberto Medeiros. Rio de Janeiro: J. Zahar, 2009. 
BAUMAN, Zygmunt. Legisladores e intérpretes. Trad. Renato Aguiar. Rio de Janeiro: J. Zahar, 2010.

CASTELLS, Manuel. A sociedade em rede - a era da informação: economia, sociedade e cultura; Volume I. São Paulo: Paz e Terra, 1999.

DERRIDA, Jacques; ROUDINESCO, Elisabeth. De que amanhã... Diálogo. Rio de Janeiro: Jorge Zahar, 2004.

DION, Nicole Annette. The Effect of Instagram on Self-Esteem and Life Satisfaction. Honors Theses. Sale State University, 2016. Disponível em: https://digitalcommons.salemstate.edu/honors_theses/91. Acesso em: 4 jun 2020.

FOUCAULT, Michel. Microfísica do Poder. RJ: Graal, 1992.

FOUCAULT, Michel. Nascimento da Biopolítica. São Paulo: Martins Fontes, 2008.

FULTON, Helen; HUISMAN, Rosemary; MURPHET, Julian; DUNN, Anne. Narrative and Media. New York: Cambridge University Press, 2005.

INSTAGRAM. Instagram Business. Disponível em: https://business.instagram.com. Acesso em: 15, abr. 2020.

MANOVICH, Lev. The Language of New Media. Cambridge, MA: MIT Press, 2001

MASSCHELEIN, Jan; SIMONS, Maarten. Em defesa da escola: uma questão pública. 2ed. Belo horizonte: Autêntica, 2014.

MILLER, Peter; ROSE, Nikolas. Governando o Presente. São Paulo: Paulus, 2012.

MOREIRA, Antonio Flávio. Qualidade na Educação e no Currículo: tensões e desafios. In: Seminário Educação de qualidade: desafios atuais., promovido pela Novamerica, Centro Cultural Poveda e Colégio Teresiano, em 27de setembro de 2008. Disponível em: https:// www.maxwell.vrac.puc-rio.br/13578/13578.PDF. Acesso em 05, fev. 2021

POPKEWITZ, Thomas S.; OLSSON, Ulf; PETERSSON, Kenneth. Sociedade da Aprendizagem, Cosmopolitismo, Saúde Pública e Prevenção à Criminalidade. In: Educação e Realidade. 34(2) maio/ago, 2009, p. 73-96.

ROSE, Nikolas. Experts of the Soul. Psychologie und Geschichte. 1991, p. 91-99.

ROSE, Nikolas. Governando a alma: a formação do eu privado. In: SILVA, Tomaz. T. (Org.) Liberdades Reguladas. Petrópolis: Vozes, 1998. 
SILVA, Tomaz Tadeu. Documentos de Identidade. Belo Horizonte: Autêntica, 2007.

TRAXLER, J. Defining, Discussing and Evaluating Mobile Learning. The International Review in Open and Distance Learning, 8(2), 2007.

URRY, John. Mobilities. London: Polity Press, 2007.

VEIGA-NETO, Alfredo; LOPES, Maura Corcini. Há teoria e método em Michel Foucault? Implicações educacionais. In: CLARETO, Sônia Maria; FERRARI, Anderson (org.). Foucault, Deleuze \& Educação. Juiz de Fora: UFJF, 2010. p. 33-47.

VEIGA-NETO, Alfredo. Currículo na Contemporaneidade: internacionalização e contextos locais. In: XI Colóquio sobre Questões Curriculares e VI Colóquio Luso-Brasileiro de Currículo. Anais do XI Colóquio sobre Questões Curriculares e VI Colóquio Luso-Brasileiro de Currículo, 2014.

WIKTOR, K. A Billion Dollar Idea: Instagram and Language Learning. from http:// bravelearning.com/2012/04/20/a-billion-dollar-idea-instagram-and-language-learning/. Acesso em: 03, jun 2020.

WILLIAMS, Raymond. Preface to second edition. Communications. 2nd Edition. London, Chatto and Windus, 1996.

\section{DAdos dos AUTORES}

\section{SANDro Bortolazzo}

Doutor em Educação pela Universidade Federal do Rio Grande do Sul (UFRGS). sandrobortolazzo@hotmail.com

\section{Roseli Belmonte Machado}

Doutora em Educação pela Universidade Federal do Rio Grande do Sul (UFRGS). Professora Adjunta na Universidade Federal do Rio Grande do Sul (UFRGS) na Escola de Educação Física, Fisioterapia e Dança.robelmont@yahoo.com.br

Submetido em: 28-02-2021

Aceito em: 01-07-2021 